\title{
Increased risk for chronic comorbid disorders in patients with inflammatory arthritis: a population based study
}

\author{
Jennie Ursum ${ }^{1 *}$, Mark MJ Nielen ${ }^{1}$, Jos WR Twisk ${ }^{2,3}$, Mike JL Peters ${ }^{4}$, François G Schellevis ${ }^{1,5}$,
}

Michael T Nurmohamed ${ }^{4,6,7}$ and Joke C Korevaar ${ }^{1}$

\begin{abstract}
Background: Studies determining the development of a wide variety of different comorbid disorders in inflammatory arthritis (IA) patients are scarce, however, this knowledge could be helpful in optimising preventive care in IA patients. The aim of this study is to establish the risk that new chronic comorbid disorders in newly diagnosed patients with IA in a primary care setting are developed.

Methods: This is a nested-case-control study from 2001-2010 using data from electronic medical patient records in general practice. In total, 3,354 patients with newly diagnosed IA were selected. Each patient was matched with two control patients of the same age and sex in the same general practice. The development of 121 chronic comorbid disorders of index and control patients was compared using Cox regression.

Results: After a median follow-up period of 2.8 years, $56 \%$ of the IA-patients had developed at least one chronic comorbid disorder after the onset of IA, compared to $46 \%$ of the control patients $(p<0.05)$. The most frequent developed comorbid disorders after the onset of IA were of cardiovascular (23\%), and musculoskeletal (17\%) origin. The highest hazard ratios (HRs) were found for anaemia (HR 2.0 [95\% Cl: 1.4-2.7]) osteoporosis (HR 1.9 [1.4-2.4]), and COPD (HR 1.8 [1.4-2.3]).

Conclusion: Patients with IA developed more chronic comorbid disorders after the onset of IA than one might expect based on age and sex. Since comorbidity has a large impact on the disease course, quality of life, and possibly on treatment itself, prevention of comorbidity should be one of the main targets in the treatment of IA patients.
\end{abstract}

Keywords: Inflammatory arthritis, Comorbidity, General practice, Disease onset, Chronic disease

\section{Background}

Inflammatory arthritis (IA) is defined as a group of chronic rheumatic diseases, including rheumatoid arthritis (RA), psoriatic arthritis (PsA) and ankylosing spondylitis (AS). These are all auto-immune diseases characterized by inflammation of joints and structural changes of bone and cartilage, with similar treatments. The prevalence of IA in general practice was 4.8 per 1000 patients in the Netherlands in 2011. In an average Dutch general practice around 2350 patients are listed, so approximately 12 patients with IA are listed in a general practice.

\footnotetext{
* Correspondence: j.ursum@nivel.nl

${ }^{1}$ NIVEL (Netherlands Institute for Health Services Research), PO Box 1568, Utrecht 3500, BN, the Netherlands

Full list of author information is available at the end of the article
}

Like many patients with a chronic disease, the majority of patients with IA have at least one other chronic disorder, the observed percentages ranged from 16 to $34 \%$ [1-5]. Several chronic diseases such as cardiovascular diseases [6,7] pulmonary diseases [8] and gastrointestinal diseases [9] are known to be increased present in IA patients [10-12]. The impact of comorbidity is high, as more chronic diseases result in more disability and diminished health related quality of life [13]. Additionally, (multiple) comorbid conditions in IA patients often lead to worse clinical outcomes [14].

Longitudinal studies in community-based settings establishing the development of a wide variety of different comorbid disorders in IA patients are scarce $[15,16]$. Up to now most studies addressing IA patients focus either 
on the development of one specific comorbid disorder or one group of disorders. Moreover, limited attention is paid to the question whether the observed frequency of newly developed chronic disorders is higher than one might expect based on age and sex, since a suitable control group is often lacking.

A few studies have indicated that the increased risk of developing new chronic diseases in IA patients might be due to a possible lack of optimal preventive care [17-19]. Therefore, it could be helpful for optimising preventive care in IA patients to know the increased risk for a broad variety of comorbid diseases.

This study aims to establish the risk that new chronic comorbid disorders in newly diagnosed patients with IA in a primary care setting are developed.

\section{Methods}

\section{Study population}

The Dutch Primary Care Database [20] is a network of, on average, 83 general practices with about 335,000 registered patients and it was started in 1994. General Practitioners (GPs) record medical information from patients routinely in electronic medical records (EMR), using the International Classification of Primary Care - version 1 (ICPC). The ICPC is a classification method for primary care encounters, accepted by the WHO [21,22]. EMRs contain information on consultations, morbidity, prescriptions, and referrals to other healthcare professionals. We have used data from the period 2001-2010. Available data are representative for the whole Dutch population [20].

\section{Selection of IA patients and controls}

We have selected all newly diagnosed patients with inflammatory arthritis (IA) aged $>30$ years, based on ICPC-code L88 - Rheumatoid arthritis and related disorders $[21,22]$. A selection purely based on this code could contain some non-IA patients, so we applied a wellestablished algorithm to exclude non-IA patients [23]. Based on this algorithm patients were included if they had a combination of specific anti-rheumatic drug prescriptions, or if they had more than one visit to their GP with code L88, or were 60 years or younger. To ensure that only newly diagnosed IA patients were included, we excluded patients with an L88-code within 365 days from start of registration. This was based on the assumption that all IA patients will go to their GP at least once a year for IA-related complaints.

To determine whether IA patients develop more chronic diseases than might be expected based on age and sex, we matched all IA-patients (index patients) with two control patients (non-IA patients, i.e. patients without an ICPC code L88) from the same general practice. The controls were matched regarding age (timeframe of
5 years) and sex. The date of diagnosis of IA was taken as the date of inclusion of the matched control. Both index and control patients were only included if they had at least 90 days of follow-up.

\section{Chronic diseases and diagnostic clusters}

The onset of one hundred and twenty-one chronic diseases was determined based on a study of O'Halloran et al., Additional file 1 [24]. All these ICPC codes were categorised within 17 ICPC chapters, such as cardiovascular, respiratory or neurological diseases (further called 'main disease groups'). Additionally, separate ICPC codes do not always give a complete picture of the disease, therefore, certain ICPC codes were combined into diagnostic clusters, for example uncomplicated hypertension (K86) and complicated hypertension (K87) were combined. These clusters were based on the selection of chronic diseases of the National Institute of Public Health and the Environment from the Netherlands [25] and the Second Dutch National Survey of General Practice [26]. An overview of the fifteen used diagnostic clusters is presented in Additional file 2.

\section{Statistical analysis}

Only chronic comorbid disorders with a prevalence of at least 2\% are presented. Gout (T92), psoriasis (S91) and osteoarthritis (OA) (diagnostic cluster) were excluded from the analysis, because these diseases may be interrelated to IA. All chronic comorbid disorders diagnosed after inclusion were indicated as newly developed. The development of new chronic diseases was tested in IA patients and control patients with a Chi-square test. Thereafter, we applied multivariable Cox regression analyses, adjusting for age, sex and number of prevalent chronic diseases at baseline, to determine the difference between IA and control patients. We performed sensitivity analyses, limiting the multivariable Cox regression analysis to 1) cases and matched controls with at least one year of follow-up, and 2) including only new chronic comorbid disorders diagnosed 90 days after inclusion. The latter restriction was chosen because the exact date of onset of chronic diseases is not always clear. A diagnosis made 90 days or more after the diagnosis IA is very likely to be an onset after the onset of IA. Finally, logistic regression was performed, by filling in the regression equation, and the absolute change for developing a chronic disease was calculated.

All statistical analyses were performed with Stata/SE 12.1 (StataCorp, College Station, TX, USA).

\section{Ethical approval}

The study was carried out according to Dutch legislation on privacy. The privacy regulation of the study was registered at the Dutch Data Protection Authority. According 
to Dutch legislation, nor obtaining informed consent nor approval by a medical ethics committee was obligatory for observational studies.

\section{Results}

We identified 3,356 patients with IA and matched 6,708 controls. The baseline characteristics are shown in Table 1. Nearly two-thirds of the patients were female (64\%), the mean age was 55 years $(\mathrm{SD}=15)$ and median follow-up duration was 2.8 years.

The number of new chronic comorbid disorders differed significantly between IA and control patients $(\mathrm{p}=0.001$, Figure 1$)$. In total, $56 \%$ of the IA patients developed one or more chronic comorbid disorder after the diagnosis of IA, compared to $46 \%$ of the control patients (Figure 1). One quarter of the IA patients developed one chronic comorbid disorder and 31\% developed two or more chronic comorbidities. Five per cent of the IA patients developed five or more chronic comorbid disorders during follow-up.

Table 2 shows only chronic diseases with a prevalence of at least $2 \%$ in IA patients or controls. In total, $23 \%$ of the IA patients and $18 \%$ of the control patients developed a cardiovascular disease (HR: $1.3(1.2-1.5)$

Table 1 Baseline characteristics

\begin{tabular}{|c|c|c|}
\hline & IA patients & Matched controls \\
\hline N (ratio 1:2) & 3,354 & 6,708 \\
\hline \multicolumn{3}{|l|}{ Sex } \\
\hline Female & $63.7 \%$ & $63.7 \%$ \\
\hline \multicolumn{3}{|l|}{ Age, years } \\
\hline Mean (sd) & $55(15)$ & $55(15)$ \\
\hline \multicolumn{3}{|c|}{ Follow-up, years } \\
\hline Median (iqr) & $2.8(1.7-4.9)$ & $2.7(1.6-4.9)$ \\
\hline \multicolumn{3}{|c|}{$\begin{array}{l}\text { Number of chronic diseases } \\
\text { at inclusion* }\end{array}$} \\
\hline Median (iqr) & $1(0-3)$ & $1(0-2)$ \\
\hline \multicolumn{3}{|c|}{ Year of inclusion, } \\
\hline 2001 & $<1 \%$ & $<1 \%$ \\
\hline 2002 & $16 \%$ & $16 \%$ \\
\hline 2003 & $12 \%$ & $12 \%$ \\
\hline 2004 & $9 \%$ & $9 \%$ \\
\hline 2005 & $10 \%$ & $10 \%$ \\
\hline 2006 & $10 \%$ & $10 \%$ \\
\hline 2007 & $13 \%$ & $13 \%$ \\
\hline 2008 & $11 \%$ & $11 \%$ \\
\hline 2009 & $11 \%$ & $11 \%$ \\
\hline 2010 & $9 \%$ & $9 \%$ \\
\hline
\end{tabular}

$\mathrm{IA}=$ inflammatory arthritis $\mathrm{sd}=$ standard deviation, iqr=interquartile range, min $=$ minimum, $\max =$ maximum.

*without IA.

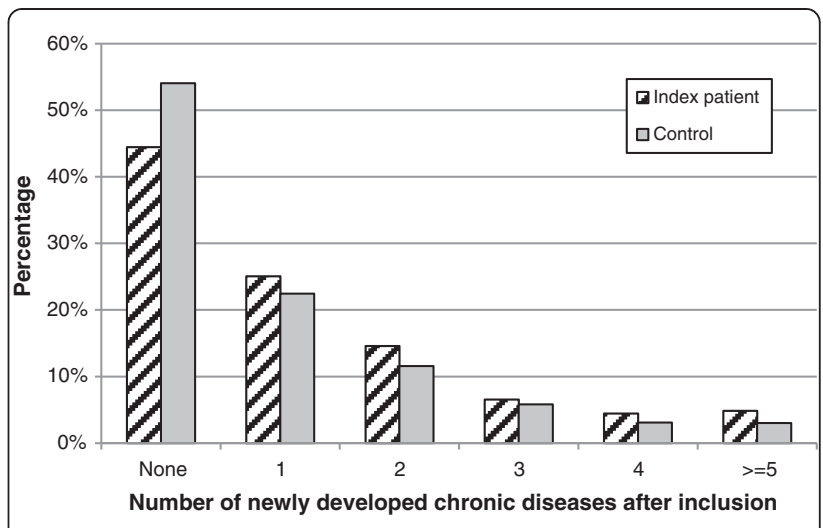

Figure 1 Percentage of patients who developed new chronic diseases after inclusion.

(Table 2). In total, $17 \%$ of the IA patients and $14 \%$ of the control patients (HR: 1.3, 95\% CI: 1.1 - 1.4) developed musculoskeletal diseases. The frequency of the remaining disease groups varied between 3 and 10\% for IA patients and 1 to $9 \%$ for control patients.

The highest risks to develop individual diseases for IA patients compared to control patients were found for anaemia (HR: 2.0), osteoporosis (HR: 1.9), COPD (HR: 1.8), carpal tunnel syndrome (HR: 1.7), and peripheral neuritis (HR 1.7).

The sensitivity analyses did not alter our findings, just all effects were slightly reduced due to a loss of power.

So what do these results mean for a specific patient in the general practice? To provide deeper insight into the risk for a specific patient, the changes to develop COPD, carpal tunnel syndrome, anaemia or heart failure were calculated, see Figure 2 and 3. Women have a higher risk to develop carpal tunnel syndrome compared to men, for the other diseases it is the other way around. The presence and the number of chronic diseases result in a higher risk to develop another chronic disease. Additionally, higher age resulted in a higher risk to develop an additional chronic disease. For example: A male of 60 years at the onset of IA without additional chronic disease has a risk of $4 \%$ to develop COPD within 2.8 yrs. A male aged 60 and with one or two chronic diseases at IA onset has a risk of 5\% risk to develop COPD within 2.8 yrs. A male aged 60 and with three or more chronic diseases at IA onset has $6 \%$ risk to develop COPD within this time frame.

\section{Discussion}

\section{Summary}

Patients develop more chronic comorbid disorders after the onset of IA than expected based on their age and sex. In a median follow-up period of 2.8 years, $56 \%$ of the IA patients have developed at least one chronic disease compared to $46 \%$ in the matched control group. Of the 
Table 2 Percentage of IA patients and control patients with new chronic comorbid disorders after diagnosis†

\begin{tabular}{|c|c|c|c|c|c|c|c|}
\hline & IA patients & Matched controls & HR crude & $95 \% \mathrm{Cl}$ & HR adjusted ${ }^{\#}$ & $95 \% \mathrm{Cl}$ & p-value \\
\hline \multicolumn{8}{|l|}{ Main disease group* } \\
\hline \multicolumn{8}{|l|}{ Diagnosis } \\
\hline Blood and blood forming organs & $3 \%$ & $1 \%$ & 2.0 & $(1.5-2.6)$ & 1.9 & $(1.4-2.6)$ & $<0.001$ \\
\hline Anaemia $^{\S}$ & $2 \%$ & $1 \%$ & 2.0 & $(1.4-2.7)$ & 2.0 & $(1.4-2.7)$ & $<0.001$ \\
\hline Respiratory & $7 \%$ & $5 \%$ & 1.6 & $(1.3-1.9)$ & 1.5 & $(1.3-1.8)$ & $<0.001$ \\
\hline $\mathrm{COPD}^{\S}$ & $4 \%$ & $2 \%$ & 1.8 & $(1.4-2.3)$ & 1.8 & $(1.4-2.3)$ & $<0.001$ \\
\hline Asthma (R96) & $4 \%$ & $3 \%$ & 1.4 & $(1.1-1.8)$ & 1.3 & $(1.0-1.7)$ & 0.015 \\
\hline Neurological & $8 \%$ & $5 \%$ & 1.5 & $(1.3-1.7)$ & 1.4 & $(1.2-1.6)$ & $<0.001$ \\
\hline Carpal tunnel syndrome (N93) & $3 \%$ & $2 \%$ & 1.8 & $(1.4-2.4)$ & 1.7 & $(1.3-2.3)$ & $<0.001$ \\
\hline Peripheral neuritis/neuropathy (N94) & $3 \%$ & $2 \%$ & 1.9 & $(1.5-2.5)$ & 1.7 & $(1.3-2.2)$ & $<0.001$ \\
\hline Psychological & $9 \%$ & $7 \%$ & 1.3 & $(1.1-1.5)$ & 1.3 & $(1.1-1.4)$ & 0.003 \\
\hline Anxiety disorder ${ }^{\S}$ & $2 \%$ & $1 \%$ & 1.5 & $(1.1-2.1)$ & 1.4 & $(1.0-2.0)$ & 0.035 \\
\hline Depressive disorder (p76) & $4 \%$ & $3 \%$ & 1.4 & $(1.1-1.8)$ & 1.4 & $(1.1-1.7)$ & 0.012 \\
\hline Cardiovascular & $23 \%$ & $18 \%$ & 1.3 & $(1.2-1.4)$ & 1.3 & $(1.2-1.5)$ & $<0.001$ \\
\hline Phlebitis/thrombophlebitis (K94) & $2 \%$ & $1 \%$ & 1.8 & $(1.3-2.4)$ & 1.7 & $(1.2-2.3)$ & 0.002 \\
\hline Varicose veins of leg (K95) & $3 \%$ & $2 \%$ & 1.4 & $(1.1-1.8)$ & 1.4 & $(1.1-1.8)$ & 0.009 \\
\hline Hypertension ${ }^{\S}$ & $12 \%$ & $9 \%$ & 1.3 & $(1.1-1.5)$ & 1.3 & $(1.1-1.5)$ & 0.001 \\
\hline Heart failure (K77) & $3 \%$ & $2 \%$ & 1.4 & $(1.1-1.9)$ & 1.5 & $(1.1-2.0)$ & 0.005 \\
\hline Digestive & $5 \%$ & $4 \%$ & 1.3 & $(1.1-1.6)$ & 1.3 & $(1.0-1.5)$ & 0.02 \\
\hline Musculoskeletal $^{\text {b }}$ & $17 \%$ & $14 \%$ & 1.3 & $(1.1-1.4)$ & 1.3 & $(1.1-1.4)$ & $<0.001$ \\
\hline Osteoporosis (L95) & $3 \%$ & $2 \%$ & 1.9 & $(1.4-2.4)$ & 1.9 & $(1.5-2.5)$ & $<0.001$ \\
\hline Spinal Cord ${ }^{5}$ & $9 \%$ & $7 \%$ & 1.4 & $(1.2-1.6)$ & 1.3 & $(1.1-1.5)$ & 0.001 \\
\hline Endocrine $^{a}$ & $10 \%$ & $9 \%$ & 1.1 & $(0.9-1.2)$ & 1.0 & $(0.9-1.2)$ & 0.514 \\
\hline \multicolumn{8}{|l|}{ Other } \\
\hline Vertiginous syndrome (H82) & $3 \%$ & $2 \%$ & 1.5 & $(1.2-1.9)$ & 1.4 & $(1.1-1.8)$ & 0.005 \\
\hline Cancer $^{\S}$ & $5 \%$ & $4 \%$ & 1.3 & $(1.1-1.6)$ & 1.3 & $(1.1-1.6)$ & 0.004 \\
\hline Eczema $^{\S}$ & $5 \%$ & $4 \%$ & 1.3 & $(1.0-1.6)$ & 1.3 & $(1.0-1.6)$ & 0.023 \\
\hline
\end{tabular}

†Patients or controls may have several chronic comorbid disorders.

*Diagnoses included are listed in supplementary file. The ICPC codes within the cluster Cancer were excluded from the main groups.

$\mathrm{HR}=$ odds ratio, $\mathrm{Cl}=$ confidence interval.

\#Adjusted for age and sex.

§Cluster.

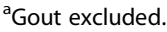

${ }^{b}$ Cluster osteoarthritis excluded.

main disease groups, cardiovascular diseases were the most common newly developed comorbidities, whereas the highest risk for individual diseases was found for anaemia, osteoporosis and COPD.

\section{Comparison with existing literature}

A study by Kapetanovic et al. found that $82 \%$ of the RA patients developed a chronic comorbid disease after disease onset [27]. This percentage is higher compared to our study (56\%), but the follow-up period was much longer, up to twenty years, and they used self-reported comorbidities instead of recorded in the EMR of the GP.

Several recent studies demonstrated that patients with IA have an increased risk of cardiovascular disease. ${ }^{10 ; 11}$
The result of our study supports this finding. However, we did not find an increased risk for some common reported cardiovascular diseases in patients with IA, like ischaemic heart disease, atrial fibrillation flutter or stroke [10-12]. These diseases might develop after a longer period than our median follow-up duration of nearly three years. We found a small but increased risk for cancer in IA patients; this finding is supported by a meta-analysis of Smitten et al. who found increased risks for several cancer types in IA patients [28].

We found an increased risk that IA patients develop COPD. This is in line with another study [29]. Patients with COPD have partly the same clinical and pathophysiological characteristics as patients with IA, like inflammation. Moreover, the inflammatory response is self-perpetuating 


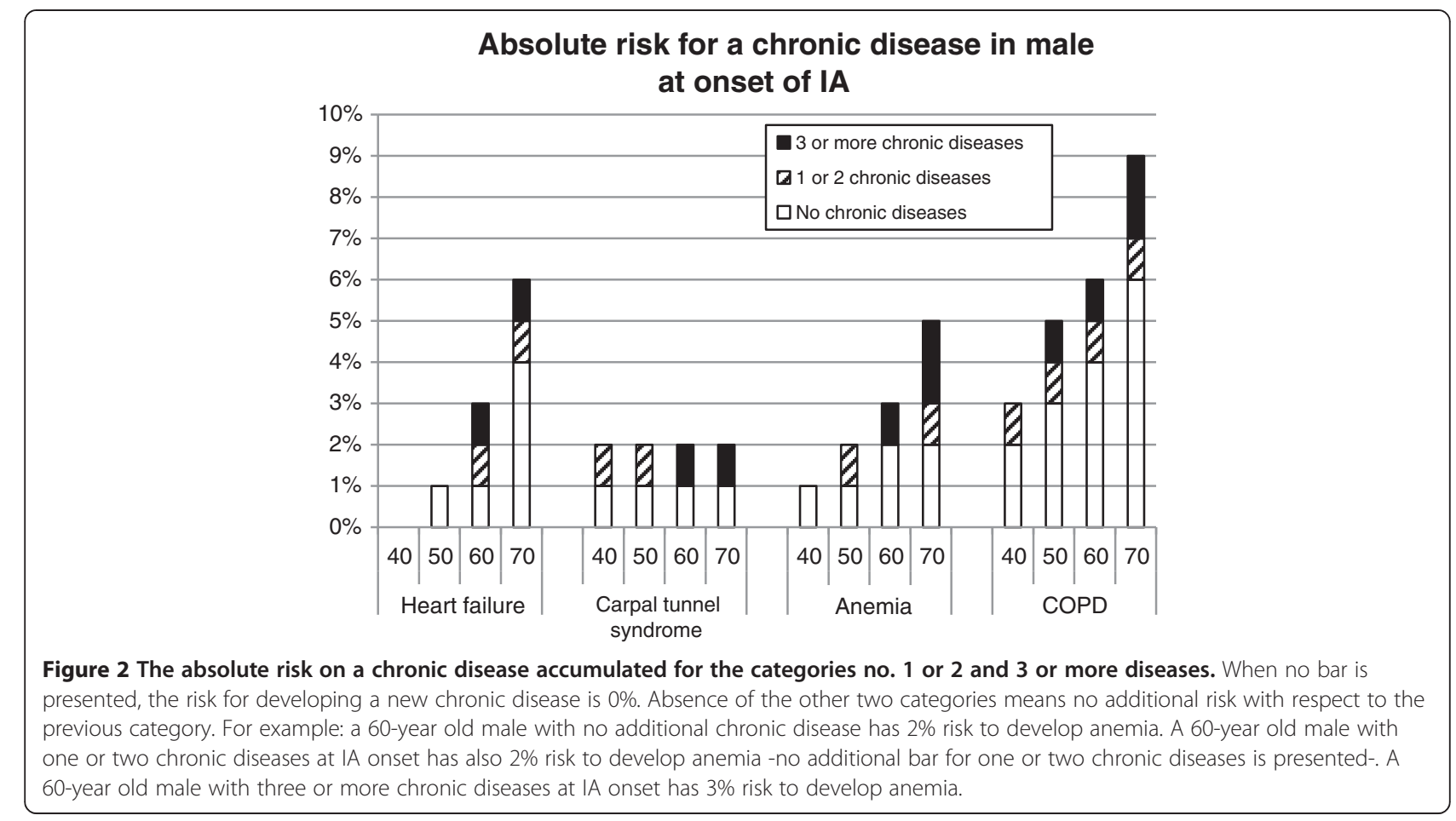

and exacerbations occur in both IA and COPD [30]. Finally, both diseases share risk factors like smoking and physical inactivity. Apart from COPD, inflammation could also play a role in the development of osteoporosis, anaemia, carpal tunnel syndrome and cardiovascular diseases [31-33]. For all these diseases an increased risk was found in the current study. Malnutrition caused by inflammation and hormonal factors may subsequently play a role in the development of osteoporosis as well as the use of glucocorticoids leading to glucocorticoid-induced osteoporosis [34-36]. Carpal tunnel syndrome might be the result of IA related inflammation as well, as

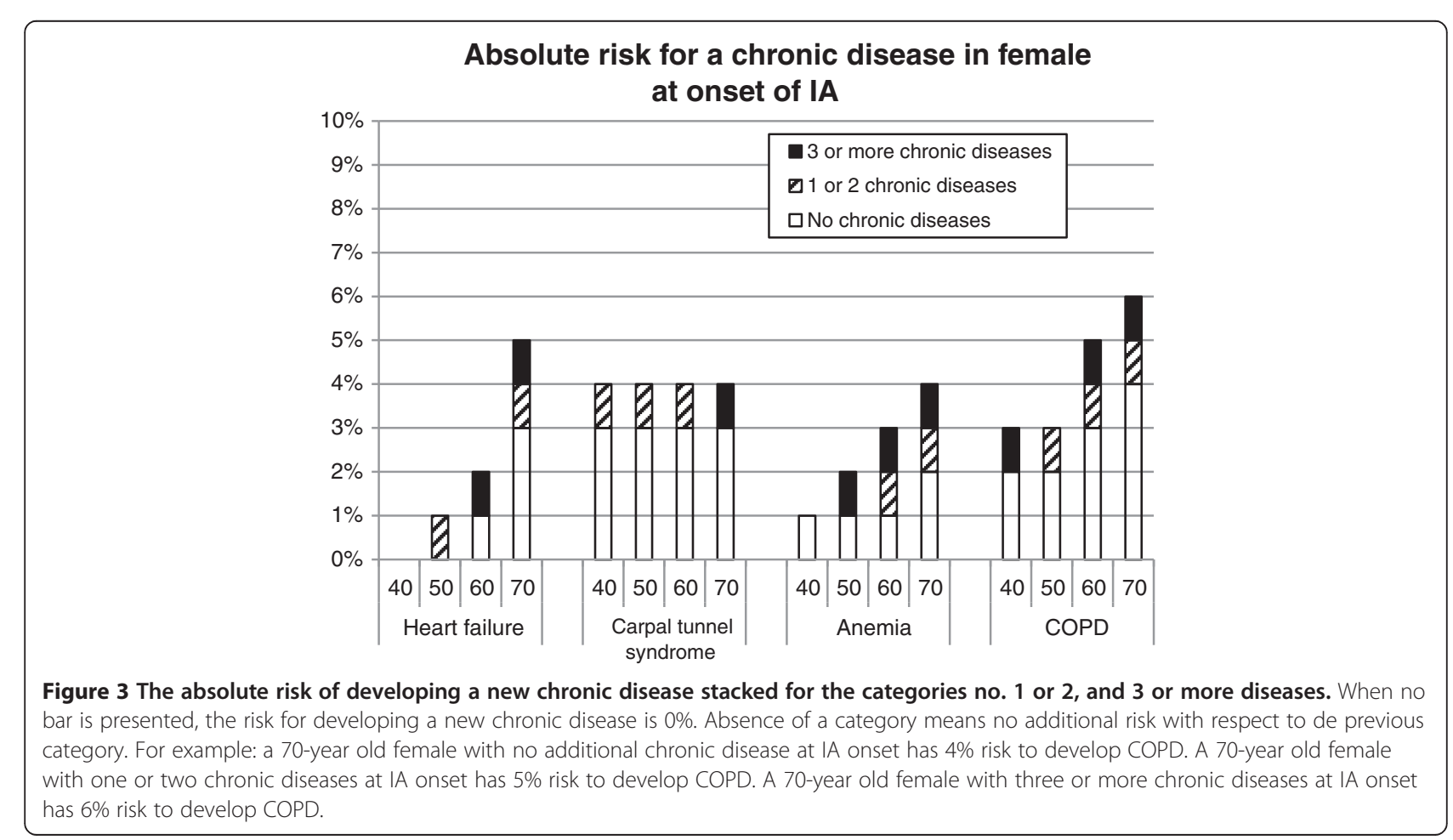


inflammation of the synovial tissue of the flexor tendons can also cause increased pressure in the carpal tunnel [33].

In our study, over half of all IA patients developed one or more new diseases within a median follow-up period of nearly 3 years. Furthermore, the newly developed diseases represent a broad spectrum of diseases, so no fixed sequence or combinations of new diseases was observed. This is confirmed in studies among patients with multimorbidity, as patients with a chronic disease often have more than one chronic disease, as multimorbidity occurs in more than two-thirds of the elderly with common chronic diseases [37]. Additionally, another study found that the cumulative incidence rates of one or more new morbidities rapidly increase with the number of morbidities already present $[38,39]$. The sequence of developing additional chronic comorbid disorders may be influenced by different factors like medication use, the combination of disease already acquired, or a common underlying mechanism [40].

\section{Strengths and limitations}

A strength of this study is that all Dutch citizens are listed within a general practice, and the GP is the first professional to be consulted for health problems. Therefore, the GP has a complete view on the patients' lifetime health status. ${ }^{37}$ Moreover, Dutch GPs obtain information of diagnosis made by the medical specialist, since the Dutch guidelines for optimising GP-medical specialist communication support medical specialists to inform GPs about the referred patient. Beside these advantages, this study has some limitations. First, we have excluded gout, osteoarthritis and psoriasis from the results, because these diseases are too much interrelated with IA. Therefore, it is difficult to conclude whether it is an isolated disease or part of IA. Patients with a combination of one of these diseases and an IA suspicion (L88 code registered) could have been misclassified. Second, we have used the ICPC code L88 to identify possible IA patients and we have used an algorithm to distinguish IA from non-IA. However, it was not possible to exclude all non-IA patients, this could have resulted in an underestimation of the true hazard ratios. Furthermore, the follow-up of three years may be too short a period to develop some chronic comorbid disorders, like e.g. ischaemic heart disease.

\section{Implications for research and/or practice}

More than half of the patients with IA developed one or more chronic diseases after the onset of IA. As inflammatory processes are a common risk factor for several other comorbidities, tight control of inflammation seems of great importance. Also, attention for other common or specific risk factors, like smoking for COPD, or glucocorticoid use for osteoporosis, can improve the primary or secondary preventive care for IA patients and may prevent or postpone the occurrence of some comorbidities. The attention for the development of chronic diseases in older patients should be intensified and also the presence of chronic diseases should be taken into account.

\section{Conclusion}

Patients with IA develop more chronic comorbid disorders after diagnosis of IA than is to be expected based on age and sex. The most frequent chronic comorbidities obtained after diagnose can be categorised in cardiovascular, musculoskeletal and neurological diseases. Since comorbidity has an impact on the disease course, on quality of life, and possibly on the treatment itself, preventive care should become a more explicit treatment target.

\section{Additional files}

Additional file 1: Table S1. ICPC codes of chronic diseases.

Additional file 2: Table S2. Overview of ICPC codes that were combined into disease clusters.

\section{Competing interests}

The authors declare that they have no competing interests.

\section{Authors' contributions}

$J U$ performed the study according to protocol, analyzed the data and wrote the manuscript. MMJN, JWRT, MJLP and JCK helped writing the manuscript and contributed substantially to the statistical analysis and interpretation of the data. JCK, FGS and MTN supervised the study and developed the study protocol. All authors read and approved the final manuscript.

\section{Acknowledgements}

We like to thank R. Davids and J. Gravestein for data management.

\section{Author details}

${ }^{1}$ NIVEL (Netherlands Institute for Health Services Research), PO Box 1568, Utrecht 3500, BN, the Netherlands. ' $E M G O+$ Institute for Health and Care Research, VU University, Amsterdam, Netherlands. ${ }^{3}$ Department of Epidemiology and Biostatistics, VU University Medical Centre, Amsterdam, Netherlands. ${ }^{4}$ Department of Internal Medicine, VU University Medical Centre, Amsterdam, Netherlands. ${ }^{5}$ Department of General Practice/EMGO Institute for Health and Care Research, VU University Medical Centre, Amsterdam, the Netherlands. 'Department of Rheumatology, VU University Medical Centre, Amsterdam, Netherlands. ${ }^{7} J a n$ van Breemen Research Institute | Reade, Amsterdam, the Netherlands.

Received: 22 August 2013 Accepted: 19 December 2013 Published: 23 December 2013

\section{References}

1. Scott DL, Symmons DP, Coulton BL, Popert AJ: Long-term outcome of treating rheumatoid arthritis: results after 20 years. Lancet 1987, 1:1108-1111.

2. Verbrugge LM, Lepkowski JM, Imanaka Y: Comorbidity and its impact on disability. Milbank Q 1989, 67:450-484.

3. Kang $\mathrm{JH}$, Chen $\mathrm{YH}$, Lin HC: Comorbidity profiles among patients with ankylosing spondylitis: a nationwide population-based study. Ann Rheum Dis 2010, 69:1165-1168.

4. Khraishi M, Macdonald D, Rampakakis E, Vaillancourt J, Sampalis JS: Prevalence of patient-reported comorbidities in early and established psoriatic arthritis cohorts. Clin Rheumatol 2011, 30:877-885. 
5. Ursum J, Korevaar JC, Twisk J, Peters MJ, Schellevis FG, Nurmohamed MT, Nielen MM: Prevalence of chronic diseases at the onset of inflammatory arthritis: a population-based study. Fam Pract 2013, 30:615-620.

6. del Rincon ID, Williams K, Stern MP, Freeman GL, Escalante A: High incidence of cardiovascular events in a rheumatoid arthritis cohort not explained by traditional cardiac risk factors. Arthritis Rheum 2001, 44:2737-2745

7. Frostegard J: Cardiovascular co-morbidity in patients with rheumatic diseases. Arthritis Res Ther 2011, 13:225.

8. Holle JU, Moosig F, Dalhoff K, Gross WL: Conditions in subjects with rheumatic diseases: pulmonary manifestations of vasculitides. Arthritis Res Ther 2011, 13:224.

9. Selmi C, De Santis M, Gershwin ME: Liver involvement in subjects with rheumatic disease. Arthritis Res Ther 2011, 13:226.

10. Mikuls TR: Co-morbidity in rheumatoid arthritis. Best Pract Res Clin Rheumatol 2003, 17:729-752.

11. Michaud K, Wolfe F: Comorbidities in rheumatoid arthritis. Best Pract Res Clin Rheumatol 2007, 21:885-906.

12. Gabriel SE, Michaud K: Epidemiological studies in incidence, prevalence, mortality, and comorbidity of the rheumatic diseases. Arthritis Res Ther 2009, 11:229.

13. Minaur NJ, Jacoby RK, Cosh JA, Taylor G, Rasker JJ: Outcome after 40 years with rheumatoid arthritis: a prospective study of function, disease activity, and mortality. J Rheumatol 2004, 21:3-8.

14. Smith SM, Soubhi H, Fortin M, Hudon C, O'Dowd T: Managing patients with multimorbidity: systematic review of interventions in primary care and community settings. BMJ 2012, 345:e5205.

15. Hochberg MC, Johnston SS, John AK: The incidence and prevalence of extra-articular and systemic manifestations in a cohort of newlydiagnosed patients with rheumatoid arthritis between 1999 and 2006. Curr Med Res Opin 2008, 24:469-480.

16. van Tuyl LH, Boers M, Lems WF, Landewe RB, Han H, Westhovens R, van Denderen JC, Westedt M, et al: Survival, comorbidities and joint damage 11 years after the COBRA combination therapy trial in early rheumatoid arthritis. Ann Rheum Dis 2010, 69:807-812.

17. Kremers HM, Bidaut-Russell M, Scott CG, Reinalda MS, Zinsmeister AR, Gabriel SE: Preventive medical services among patients with rheumatoid arthritis. J Rheumato/ 2003, 30:1940-1947.

18. Gabriel SE: Why do people with rheumatoid arthritis still die prematurely? Ann Rheum Dis 2008, 67:iii30-iii34.

19. Probst-Hensch N, Tanner M, Kessler C, Burri C, Kunzli N: Prevention-a costeffective way to fight the non-communicable disease epidemic: an academic perspective of the United Nations High-level NCD Meeting. Swiss Med Wkly 2011, 141:w13266.

20. Netherlands Information Network General Practise (LINH). Facts and figures on General Practise care in the Netherlands. http://www.nivel.nl/ en/netherlands-information-network-general-practice-linh], accessed 17 juli 2012.

21. Lamberts H, Wood M: International Classification of Primary Care. Oxford: Oxford University Press; 1987

22. Lamberts H, Wood M: The birth of the International Classification of Primary Care (ICPC). Serendipity at the border of Lac Leman. Fam Pract 2002, 19:433-435.

23. Nielen MM, Ursum J, Schellevis FG, Korevaar JC: The validity of the diagnosis of inflammatory arthritis in a large population-based primary care database. BMC Fam Pract 2013, 14:79.

24. O'Halloran J, Miller GC, Britt H: Defining chronic conditions for primary care with ICPC-2. Fam Pract 2004, 21:381-386.

25. Hoeymans N, van Oostrom SH, Gijsen R, Schellevis FG: Selectie van chronische ziekten. In Volksgezondheid Toekomst Verkenning, Nationaal Kompas Volksgezondheid. Bilthoven: RIVM; 2013. http://www.nationaalkompas.nl.

26. van der Linden M, Westert GP, de Bakker DH, Schellevis FG: Tweede Nationale Studie naar ziekten en verrichtingen in de huisartspraktijk. Klachten en aandoeningen in de bevolking en in de huisartspraktijk. Utrecht/Bilthoven: NIVEL/RIVM; 2004.

27. Kapetanovic MC, Lindqvist E, Simonsson M, Geborek P, Saxne T, Eberhardt K Prevalence and predictive factors of comorbidity in rheumatoid arthritis patients monitored prospectively from disease onset up to 20 years: lack of association between inflammation and cardiovascular disease. Scand J Rheumatol 2010, 39:353-359.
28. Smitten AL, Simon TA, Hochberg MC, Suissa S: A meta-analysis of the incidence of malignancy in adult patients with rheumatoid arthritis. Arthritis Res Ther 2008, 10:R45.

29. Schnell K, Weiss CO, Lee T, Krishnan JA, Leff B, Wolff JL, Boyd C: The prevalence of clinically-relevant comorbid conditions in patients with physician-diagnosed COPD: a cross-sectional study using data from NHANES 1999-2008. BMC Pulm Med 2012, 12:26.

30. Agusti A, MacNee W, Donaldson K, Cosio M: Hypothesis: does COPD have an autoimmune component? Thorax 2003, 58:832-834.

31. Means RT Jr, Krantz SB: Progress in understanding the pathogenesis of the anemia of chronic disease. Blood 1992, 80:1639-1647.

32. Peters MJ, Nielen MM, Raterman HG, Verheij RA, Schellevis FG, Nurmohamed MT: Increased cardiovascular disease in patients with inflammatory arthritis in primary care: a cross-sectional observation. J Rheumatol 2009, 36:1866-1868.

33. Ibrahim I, Khan WS, Goddard N, Smitham P: Carpal tunnel syndrome: a review of the recent literature. Open Orthop J 2012, 6:69-76.

34. Jorgensen NR, Schwarz P: Osteoporosis in chronic obstructive pulmonary disease patients. Curr Opin Pulm Med 2008, 14:122-127.

35. den Uyl D, Bultink IE, Lems WF: Glucocorticoid-induced osteoporosis. Clin Exp Rheumatol 2011, 29:S93-S98.

36. Montalcini T, Romeo S, Ferro Y, Migliaccio V, Gazzaruso C, Pujia A: Osteoporosis in chronic inflammatory disease: the role of malnutrition. Endocrine 2013, 43:59-64

37. van Oostrom SH, Picavet HS, van Gelder BM, Lemmens LC, Hoeymans N, van Dijk CE, Verheij RA, Schellevis FG, Baan CA: Multimorbidity and comorbidity in the Dutch population - data from general practices. BMC Public Health 2012, 12:715.

38. van den Akker M, Buntinx F, Metsemakers JF, Roos S, Knottnerus JA: Multimorbidity in general practice: prevalence, incidence, and determinants of co-occurring chronic and recurrent diseases. J Clin Epidemiol 1998, 51:367-375.

39. Lappenschaar M, Hommersom A, Lucas PJ, Lagro J, Visscher S, Korevaar JC, Schellevis FG: Multilevel temporal Bayesian networks can model longitudinal change in multimorbidity. J Clin Epidemiol 2013, 66:1405-1416

40. Gijsen R, Hoeymans N, Schellevis FG, Ruwaard D, Satariano WA, van den Bos GA: Causes and consequences of comorbidity: a review. J Clin Epidemiol 2001, 54:661-674.

doi:10.1186/1471-2296-14-199

Cite this article as: Ursum et al:: Increased risk for chronic comorbid disorders in patients with inflammatory arthritis: a population based study. BMC Family Practice 2013 14:199.

\section{Submit your next manuscript to BioMed Central and take full advantage of:}

- Convenient online submission

- Thorough peer review

- No space constraints or color figure charges

- Immediate publication on acceptance

- Inclusion in PubMed, CAS, Scopus and Google Scholar

- Research which is freely available for redistribution 